\title{
Temporal Issues in Information and Communication Technology-Enabled Organizational Change: Evidence From an Enterprise Systems Implementation
}

\author{
Steve Sawyer \\ School of Information Sciences and Technology, Pennsylvania State University, \\ University Park, Pennsylvania, USA
}

\section{Richard Southwick}

School of Information Studies, Syracuse University, Syracuse, New York, USA

In this article we highlight temporal effects in information and communication technology-enabled organizational change. Examples of temporal effects are explored in the context of one organization's efforts to implement an enterprise-wide information system. Temporality is presented as having two aspects, with the first being the well-recognized, linear and measured clock time. The second aspect of time is that which is perceived-often as nonlinear-and socially defined. We find that temporal effects arise both in changes to the structure of work and in differences among groups in how time is perceived. Evidence suggests that both specific characteristics of the implementation and of the enterprise systems' technologies further exacerbate these temporal effects. We conclude with suggestions for how to incorporate a temporally reflective perspective into analysis of technology-enabled organizational change and how a temporal perspective provides insight into both the social and technical aspects of the sociotechnical nature of enterprise systems.

Received 26 June 2000; accepted 16 October 2001.

The authors gratefully acknowledge the invaluable comments made on earlier drafts of this article by Allen Bluedorn, Kevin Crowston, Robert Heckman, Barbara Kwasnik, Allen Lee, Heejin Lee, Edgar Whitley, Ping Zhang, and three anonymous reviewers. Portions of this article were first presented at the 1997 IFIP8.2 Working Conference on Qualitative Research in Information Systems. This research has been supported in part by the Vice-President for Research and Computing and the Dean of the School of Information Studies at Syracuse University.

Address correspondence to Steve Sawyer, School of Information Sciences and Technology, Pennsylvania State University, 513 Rider I Building, 120 S. Burrowes St., State College, PA 16801, USA. E-mail: sawyer@ist.psu.edu; web site: http://www.ist.psu.edu
Keywords enterprise systems, ICT, IT, implementation, time, organizational change, research methods, sociotechnical systems

We examine how temporality - the social context formed by time-influences the phenomena of organizational change associated with the implementation of enterprise-wide information systems. Increasingly, scholars have noted that the influence of time is not well accounted for in social science research (Hall, 1959; Kelly \& McGrath, 1988; Abbott, 1995; Bluedorn, 2000; Avital, 2000). In particular, contemporary information systems scholars highlight that the influence of time has not been a focal issue in studies of the roles of information and communication technologies, and the information systems in which they are embedded, in social organization (e.g., Lee, 1999; Lee \& Liebenau, 2000).

Here we conceptualize the influence of time in enterprise-wide information systems (enterprise systems or ES) implementations as occurring at two levels. First, there is the objective aspect of time, revealed in the tools and techniques of project management, such as Gantt charts. These represent time linearly and serve the important and frequently problematic concern in information systems implementation projects with marking events and maintaining deadlines. Second, and of particular concern for us, time can be viewed as a contributor to the dynamic and subjectively formed context within which the social actors define and plan their activities. Here, perceptions of time serve as foundation s of the actors' social reality. 
Drawing on our empirical work on the implementation of an enterprise system in one organization, we discuss the value of a temporal perspective on information system uses in organizations. For many readers this article can be best valued by its authentic, plausible, and critical contribution s to the emerging discussion on the temporal nature of information systems in social organization (e.g., Golden-Biddle \& Locke, 1993). Readers may further value this article for its engagement of issues regarding time and method (see Kelly \& McGrath, 1988, p. 11). Some readers may also value the focus on the enterprise system implementation as providing a revelatory case on large-scale (enterprise-level) technology-enable d change (Yin, 1984, p. 48). Beyond these considered perspectives, our overarching goal is to spur interest in, and attention toward, temporal issues relative to the uses of information systems in social organization.

Following a short discussion about what we mean by enterprise systems, this article continues in five parts. In the first part we present a discussion of time and the characterization of a temporal approach to research. In part two we discuss particular characteristics of the act of implementation and the features of the enterprise system technologies that highlight the importance of understanding temporality's role in such technology-enable d changes. In the third part we illustrate these issues by drawing from our empirical work on the implementation of an enterprise system at Mid-Sized University (MSU). In part four we discuss two findings that arise from our analysis: temporal asymmetries among groups and the move toward polychronic work. In the final part of this article we present implications of this temporal focus on the practices of researching technology-enable d change in social organizations .

\section{ENTERPRISE SYSTEMS}

An enterprise system is a specific type of an information system. Enterprise systems are characterized by a suite of integrated software modules and a common database used to help manage a company's human resources, financials, and the service and/or manufacturing processes. While often described as an integrated system that offers a broad range of functional modules that share a common database, typically, enterprise systems are collections of packaged software components. These are labeled as enterprise systems because their functionality incorporates most major function s of an organization. Enterprise systems often replace collections of independent software modules acquired from multiple vendors, along with custom applications traditionally written and maintained by in-house information technology departments (Francalanci, 2001; Sawyer, 2001).

In this article we conceptualize an enterprise system as a sociotechnical ensemble (Orlikwoski \& Iacono, 2001).
An ensemble view encompasses the functionality in the software, the various computing components that support and house the software, the connection s to people and processes that both span and link the organization's administrative structures, and the roles of the people involved (Kling \& Scacchi, 1982; Fleck, 1994).

Through the 1990s organizational leaders increasingly chose to adopt enterprise systems with the belief that they would improve the ability of their organization to achieve its goals (e.g., maximize shareholder value, serve the public, educate students, etc.), and to respond to technical issues with each existing system's compliance-such as concerns for Year 2000 compatibility. This movement toward the purchase of enterprise systems from vendors helped to fuel the growth of the packaged software market. For example, by 1998 the market for packaged software grew to $\$ 140$ billion of the $\$ 200$ billion software market. Of this $\$ 140$ billion, $25 \%$ of the sales were for system software, leaving application packages to account for \$105 billion (OECD, 1998). Annual sales of enterprise systems software are growing faster than in all other segments. Sales of these systems accounted for \$10 billion in 1998. Forrester Research (1998) further reports that spending on services (such as systems implementation, training, and process reengineering support) has been growing at $16 \%$ per annum for more than a decade and accounted for $\$ 180$ billion in 1997. More than 50\% of this total was in support of enterprise system implementations.

Simply, the move toward organizational adoption of enterprise systems has been dramatic both for organizations and for the information technology industry (Sawyer, 2001 ). The move toward purchasing enterprise systems has also been controversial (Markus \& Tanis, 2000). For example, Hammer (1999) argues that this is "the most potent and subversive contemporary instrument of busines s revolution." Certainly, many firms choose to adopt/implement enterprise systems to enable strategic outcomes and expect substantial process and organizational changes. However, even in firms that seek tactical outcomes (such as Year 2000 compliance, improved data integration, and/or reduced technology maintenance costs), adoption often leads to substantial changes (in processes and structures) that have strategic implications. In the remainder of this article we examine the temporal perspective of such change.

\section{A TEMPORAL PERSPECTIVE}

To examine the ways in which enterprise systems help to alter organizations, we employ a temporal perspective. Bucciarelli's (1988) interpretation s of time in engineering design help illustrate our view of temporality. Bucciarelli posits two worlds in the temporal process: an "objectworld" defined by topicality, and a "process-world" defined by social narrative. We extend his analysis to the 
enterprise software implementation process. The objectworld refers to the physical elements of computer technology, such as hardware and software. These "objects" find temporal definition through the artifacts of project management. Like the engineering example, the enterprise system implementation process-world refers to the "world of dialogue and negotiation, of social exchange, laughter, gossip, banter-all that which is ever-present in design, but whose significance is generally discounted" (Bucciarelli, 1988, pp. 96-97).

The task of accommodating the process-world view in information systems research is essential in understanding the way that time contributes to the development of the overall social context of an organization. Our overall interest in the present study has been with how organizational changes are manifested in concert with the introduction of enterprise-level information systems. We are primarily interested in deliberate organizational change: that is, an intended action to force a departure from the current state to some future state (Beckhard \& Harris, 1987; Benjamin \& Levinson, 1987; Markus \& Benjamin, 1997), while acknowledging that organizational change is inevitably an unintended as well as an intended outcome (Sproull \& Kiesler, 1991). Therefore, we are concerned with how individuals and groups within the organization engage in activities intended to accomplish specific goals and objectives relative to the use of enterprise systems. These activitie s become manifest through the social interactions among project participants (Hirschheim, Klein, \& Newman, 1991). The social actors subjectively interpret or make sense of these interactions through the subjective frames of reference that they have constructed through prior experience. One important contributor to the actors' frame of reference is through interpretation s of time.

In sum, the influence of social context has been a central element of our research and we propose that an understanding of temporality follows logically in this regard. Clearly, the social constituency of a typical large-scale technology implementation project is complex, involving multiple stakeholders from outside the core organization (i.e., vendors and consultants) and from within (i.e., functional units, internal technologists, administrators, etc.). This suggests that the actors' (project participants) interpretations of time are not necessarily uniform to the degree that they have been formed in particular social contexts. Therefore, as we try to fit a temporal framework to the social endeavor of implementing an enterprise system, an important consideration must be in accommodating a perspective that allows conflicting, as well as consensual assumptions about working relationships as they may be impacted by the influences of time.

Barley (1988) provides useful guidance in this regard. Building on the work of Zerubavel (1979, 1981), his longitudinal study of work organization in radiology departments implementing new technologies serves to highlight that temporal order can structure relation s among groups. Barley's study centers on the conflict between the technicians (as users) and the radiologists (as users). He posits a recurring dynamic between external, objective aspects of temporal order (structural) and its social constructedness. Barley describes how the technology-base d temporal order affects the way individuals and groups interpret their work. He further argues that temporal asymmetries can be a source of conflict among organizational groups. Based on observation s in our own study, we posit time to be an important element in constructing a conceptual framework for examining the social dynamic among users, technologists, and vendors: a framework characterized by consensual and conflicting forces working toward a homeostatic working state for the project participants as a collective.

As we detail later, our data indicate that temporal issues manifest themselves across several levels of analysis. First, temporal issues span the individual-to-workgrou p level, where changes to the temporal structure of work are most prominent. Here, perceptions of time tend to become increasingly polychronic (vs. monochronic) (see Bluedorn, Kauffman, \& Lane, 1992; Slocombe \& Bluedorn, 1999). In the context of work, polychronicity means that tasks are less sequentially ordered and more frequently done in parallel. For instance, the implementation project teams at our research site could not independently conduct needs analyses without involving other teams. Thus, each team was subject to interruption s from other teams as a natural part of their work. This means that individual workers must adjust to working on, and switching among, multiple tasks.

There are also temporal effects at the organizational level. For instance, our data show that temporal asymmetries among functionally distinct groups of stakeholders (i.e., technologist and nontechnologis t) were becoming more pronounced, and, in some cases potentially debilitating in terms of the progress of the project. Temporal asymmetries reflect differing perceptions on time among different groups of people (Barley, 1988). For instance, time and pace differences existed between the consultants and the line staff at the research site. Consultants pressed to move more quickly to install the new technical functionality because they felt that technical changes were moving too slowly. At the same time, the line staff worried about moving too fast with the changeover to the new functionality.

From the perspective of practicing professionals, temporal issues are both well known and often well accounted for by those who manage, consult, or build products for projects involving technology-enabled organizational change. For example, temporal asymmetries among stakeholder groups often serve as a useful lever for managers. 
That is, managers can use the differing perceptions of time as a mechanism to instill urgency in the different groups by highlighting temporal differences. For instance, creating an artificial deadline is one way to create different perceptions of time and encourage some short-term motivation. A second point of leverage for managers is to use temporal asymmetries as a form of "insulation" or buffering. While many successful managers often intuitively grasp the value of manipulating perceptions of time (see Bluedorn, Kauffman, \& Lane, 1992; Vinton, 1992), there are also unintended, and often unseen, consequences that we briefly discuss near the article's end.

These examples provide some evidence that there are differences between temporal and nontemporal perspectives. A temporal perspective provides insight into the way individuals relate to their work (tasks) and to change. A temporal view also allows for greater insight into the possible sources of conflict among groups and on issues with how differing work groups adjust their work to better coalign. Each of these insights is masked where traditional views of time (as linear and stable) are used.

\section{FACTORS AFFECTING TEMPORALITY IN TECHNOLOGY-ENABLED CHANGE}

The need to account for a temporal perspective in order to bring about a successful computer systems implementation has been discussed in the literature (i.e., Brooks, 1974; Failla \& Bagnara, 1992) but not explored in great depth (i.e., Lee, 1999). For instance, in reflecting on his experiences with software development projects, Brooks (1974) illustrates how traditional conceptions of timethat is, as linear and additive - may lead to inaccurate hypotheses within the complexity of a social context. As reflected in the title of his book, The Mythical Man-Month, he relates how assuming that one might hasten the completion of a project by assigning more people to it was not only wrong, but also likely to produce the counterintuitive effects. Brooks conveys the lesson that in software development projects, where social complexity interacts with the demands of software development tasks, success also depends on recognizing social factors. Clearly, one of these social factors is the way time is seen and structured by the participants themselves. Drawing on existing literature, we identify two categories of factors that further heighten the effects of temporality: specific implementation characteristics and specific features of the enterprise systems (Fleck, 1994; Markus \& Tanis, 2000). In this part of the article these two factors, and their effects, are described and presented (see also the left-hand column of Table 1). We go on to use these two factors to guide our examination of temporal issues in the specific context of MSU's enterprise systems implementation.

\section{Specific Implementation Characteristics}

At least three characteristics of enterprise systems implementation efforts heighten the differential effects of time: involvement of multiple parties, consequences due to multiple effects seen at multiple levels, and environmental (context) pressures. The increased number of involved parties (stakeholders) implies the need for increased communication and coordination among these groups. Since each group builds its own perception of time based on aspects of the implementation effort it deems most important, differences in the perceptions of time among these groups are common.

For instance, during implementation, there are at least three sets of relations in which perceptions of time and timing are likely to differ. The first set of relations is those among the vendors (the developers of software) and the technologists (members of the organization's information systems group). The second set of relations exists between the technology vendors and the organizational users of the enterprise system. The third set of relations exists among the technologists and the users.

The first set of relation s is relatively new to the organization's technologists. As we stated earlier, purchasing an enterprise system means that the organization's information systems staff is no longer developing software (Sawyer, 2001). The result has been that technology vendors are far more integral than previously to most organizations' computing infrastructure. The technologist s have become responsible for overseeing what they used to do for a living, and their role has transformed toward an increasing emphasis on managing organizational change (e.g., Markus \& Benjamin, 1997). These two groups of stakeholders may develop differing views on the pace of product delivery, the rapidity (and perhaps ease) of technical acceptance of new products, and the pace of interaction (such as placing calls and expecting a certain speed of response in return). Moreover, as information and communication technologies are distributed, previously centralized technologist s may also be dispersed (Eschenfelder, Heckman, \& Sawyer, 1998).

Differences in user/developer temporal relationship have always existed. However, because the developers (vendors) are not colocated at the host organization, it is now a relationship mediated by geographic distance. The users have an even smaller voice, since their connections to vendors are mediated through help desks, user groups, and survey feedback (Keil \& Carmel, 1995). The final set of relations between the users and the technologists has changed in that these two groups are now both more dependent on the speed of delivery (for products and services) from technolog y vendors. However, the long history between the two creates a set of social structures that seem to mask their current similarities. For example, our data suggest that the perception by users - that internal 
TABLE 1

Factors influencing temporality in ES implementation s

Factor

Specific implementation characteristics

Multiple stakeholders

Multiple effects at multiple levels

Environmental pressures

Specific features of the ES technologies

Product immaturity

Composite nature of infrastructure

Infrastructure complexity
Evidence at MSU
ES (and other) vendors, technologists (central and distributed), and users all interdependent and operating with different assumptions and perceptions

Differences among the various groups

Difficulties experienced by technologists in managing the project(s)

Year 2000 planning

Removing legacy systems/restrictions

Desire to retrain IT staff due to workforce shortage

Products are often not available when needed

Multiple releases of product (perpetual development)

Multiple vendors

Multiple and overlapping product trajectories

Constant need to upgrade (slightly incompatible) hardware and software components

Multiple products and projects, many of them in flux

Pervasive integration of computing into work technologist s are not very responsive or accessible-is not changed by the fact that technologists now include users in every decision about the technology vendor's packages.

One consequence of multiple effects at multiple levels is reflected in the differential rates of acceptance of change across levels of the organization's hierarchies. For example, senior leadership may more quickly agree to adopt new business processes while the affected workers may be far less accepting. Conversely, adoption of new (and more effective) ways of working at lower levels may not be welcomed at middle levels in the organization s (Brown $\&$ Eisenhardt, 1997). In both cases, one party is "moving faster" relative to acceptance than is the other, and this leads to a temporal asymmetry between the groups.

Environmental pressures that exacerbate temporal effects include both the need to address technical exigencies (e.g., the Year 2000 concerns, which became a central issue in most information systems groups in the later 1990s) and a shortage of skilled workers who have both knowledge of the new enterprise technologies and experience with implementing large-scale change to an organization, which these systems require. Another influence of time in the implementation of enterprise systems is that these products are in a perpetual state of product development. That is, the software matures via releases, with each release involving changes to the software, hardware requirements, and perhaps roles and rules of use, and even norms around that use.
Participating in this evolutionary development process are departmental system users, technologists within the host organization, and external vendors (such as consultants supporting the implementation and the systems [vendor's] developers ). The induced loyalty and market power of an installed base for an enterprise system mean that each new release brings money to the vendor-a strong incentive to always be in product development (Brynjolfsson, 1994; Carmel \& Sawyer, 1998).

Associated with the organizational process of deploying an enterprise system are the artifacts that the organizational actors themselves use to impose administrative order. These are the tools of project management. The most obvious example is the milestone chart, an instrument for measuring objective time. Milestone charts also reflect a long-standing tradition in organizational studies where time is understood to be a commodity that is objective, linear, homogeneous, and divisible (able to be partitioned by rational human mental process), with a value commensurate with its divisible parts (Hassard, 1996).

\section{Features of the Enterprise Systems}

Enterprise systems are vendor provided, so they are not fully customized for any one user. Once purchased, these systems often require extensive tailoring of both the package's functions and the organization's work practices. This 
suggests that the functionality that an enterprise system encompasses is both nonlinear in its arrival and often not predictable in its use (Fleck, 1994; Liker, Roitman, \& Roskies, 1987). There are several features of these systems and the underlying technologies that help to shape temporal effects: the product's immaturity, the composite nature of the underlying technologies, and the resulting infrastructure's complexity.

The first technology feature is the relative immaturity of the software. Often, these products are not complete when sold and exist as "beta" or prerelease copies for months prior to a full release. Part of the reason for this immaturity is that many technology vendors are "porting" or rewriting their code to move it from mainframe-based to client/server platforms. More recently these vendors have also begun to adapt their products for Internet-based use. All these changes lead to product instability - many releases, and ambiguity on "ship" date (when the new release will be ready) and content (actual functionality). This means that products may be shipped that have critical features (perhaps even entire modules) unavailable, incomplete, or not useful as provided.

Another force influencing product immaturity is the competitive pressures that encourage enterprise system's vendors to release products as quickly as possible in order to capture market share and/or meet financial expectation s (Carmel \& Sawyer, 1998). Pressures to ship software often lead to faulty (bug-ridden) products. Fixing these bugs leads to unwelcome rework for the vendor as it releases patches to fix problems with interim releases of an incomplete product. Unstable products also affect the installing organization's ability to implement and use the enterprise system.

A second technology feature that influences the temporal aspects of enterprise systems implementation is the composite nature of the base technologies. There are two parts to this. First, the distributed computing infrastructures on which these systems "live" are actually collections of distinct components that are typically made by many vendors. This means that any organization's computing base is a customized collection of hardware, software, and cabling/media. And, as noted earlier, many of the base technologies are relatively immature, evolving toward de facto standards of interoperability. These standards are often both hotly contested (for instance, the battle among network operating systems such as Unix, Novell, and Microsoft) and loosely interpreted (which means that two products that comply to the "same" standard still may not operate well together). Second, many of the enterprise software packages are also composites of several products. That is, any particular enterprise system has many modules and some of these modules may be developed by subcontractors. These different firms are either acquired by purchase or contracted for sole source production. This leads to the potential for problems with operational interoperability and stability of the product.

This multi-vendor-supplie d component approach to building computing infrastructures and the broad interpretations of standards mean it is difficult for vendors to predict how their products will behave in the field. Further, each of these component products is developed on an individualistic timetable. This means that the interdependent components of an organization's computing infrastructure are changing at various, independent, rates. The concept of an organization's computing infrastructure following a particular technical trajectory (e.g., Quintas, 1994; Fleck, 1994) assumes a common direction for all components. Given the large number of different vendors' component technologies, the empirical reality is that there are multiple trajectories of these various products and that these trajectories are neither parallel nor time sequenced to move together. Further, the blending of technology components leads to the creation of unique computing infrastructures, limiting the value of external technical help in supporting these unique collections (Eschenfelder, Heckman, \& Sawyer, 1998).

A third feature of enterprise systems with temporal implications is their inherent complexity, which makes it difficult to prepare workers to use them. Enterprise systems integrate a broad range of functions and can be customized to better reflect the implementing organization's existing and/or desired work processes. Their use requires advanced computer system knowledge (such as icon-based interfaces and an understanding of client/server architectures). The assumption of either a common knowledge of this technical know-how or a belief that there is a linear learning curve for affected workers fits with project management rationalization s of time, but sits awkwardly with users and empirical evidence (e.g., Baronas \& Louis, 1988; Liker et al., 1987; Burkhardt, 1994; Fleck, 1994).

\section{TEMPORAL ISSUES IN MSU'S COMPUTING TRANSITION}

In this part of the article we use our research on an enterprise systems implementation at MSU as an example of how a temporal perspective can be used to examine technology-enable d organizational change. In the remainder of this section we outline our research approach, research setting, data collection, and analysis.

\section{Research Approach}

Following the objectives and assumption s outlined later in this section, we employed a longitudinal, field-based approach for studying organizational change at MSU. Zuboff (1988, p. 423) began her own discussion of her methodology by saying, "Behind every method is a belief." Our belief is that longitudinal, in situ fieldwork is well suited 
for research that seeks to understand the temporal aspects of technology-enable d organizational change (Van Maanen, 1995; Barley, 1986, 1990).

This belief is guided by the following four assumptions: (1) Our perspective on change is social. While change may manifest itself in some physical form or artifact, in order to develop useful knowledge of the phenomenon, it is necessary to elicit the socially constructed interpretation s of the organizational actors that they develop through their social interactions (Markus, 1983). (2) An actor's interpretation s of the events are part of a larger, dynamic social context and therefore must be interpreted as situationally dependent. This perspective incorporates the social and physical aspects of computing into the concept of an infrastructure (Kling \& Scacchi, 1982; Kling, 1992). (3) The situationally dependent, socially interpreted foundation for social (organizational) action makes prediction based on a single event or a single actor's actions impossible. In other words, we take an emergent perspective on the relationship between information technology and the organization (Markus \& Robey, 1988). (4) In taking an interpretive perspective, we as researchers cannot be detached from the social context. Therefore our observation s are necessarily subjective, and this has implication s for the conduct of the research (i.e., Barley, 1990).

Adopting a temporal perspective to conducting research further requires us to examine the ways that events (in this case, issues with technology-enable d organizational change) unfold across time. This stands in contrast to variance models of research that focus on relationships between variables and measures of antecedents and outcomes (Mohr, 1982; Markus \& Robey, 1988). However, longitudinal, process models of research often provide a limited (linear) perspective on time (Abbott, 1995). The importance of cycle and ritual-key aspects underlying the social organization of work-is often subsumed by the omnipresent linearity of objective time (Friedman, 1990; Macey, 1989). As Jones (1988, p. 21) says, "All human events occur in time. But the character of those events and the time in which they occur vary widely from person to person, from culture to culture."

Therefore, in addition to accounting for the linearity of time through longitudinal methods, it is also necessary to establish reasons behind the temporal pacing and interconnectedness of events. This is illustrated in studies centering on the clock as a symbol of temporal influences on organization (Lee, 1999; Friedman, 1990; Macey, 1989; Young, 1988). The clock is useful in gaining a view that is cyclic as well as linear. For instance, Young (1988) describes how the cyclic rituals of night nurses in an English hospital defy linear description. Many of the sequences depend on the "sense-making" of the nurses as they conduct their rounds, making it difficult to lay out an accurate set of business processes. This same paradox-between objective and perceived time-arises in the development of work-flow systems to support creative or knowledgeintensive work (e.g., Reder \& Schwab, 1990). Work-flow systems are built on linear sequencing, while most people work in cycles (e.g., the status report is due each Friday, the staff meeting is always held on Wednesday... ). In these and other cases it is necessary to delve beneath standard norms and procedures to examine the temporal nature of these behaviors.

\section{The Research Setting: Mid-Sized University}

The host site, MSU, is a private, research-oriented university. It enjoys high name recognition, nationally and internationally. MSU's administrative and organizational structures are representative of typical American universities of nearly 18,000 students and 4,000 employees. However, by 1993, three environmental factors constraining MSU's computing infrastructure created a situation demanding senior management attention. These were: (1) an increasing work load required of MSU's mainframe systems, (2) a restrictive reliance on MSU's outdated legacy systems, and (3) an increasingly unmanageable tangle of administrative and academic networks, characterized by overlapping links and disparate technologies .

These issues are typical of most academic computing systems (Alpert, 1985; El-Khawis, 1995; McClure \& Lopata, 1996; Swartz \& Orgill, 2001) and many other mid-sized and large organizations. Facing this scenario, MSU's chief information officer (CIO) made the decision to revamp the computing infrastructure to take advantage of new client/server technology. The CIO reflected that this was "as much a decision on saving money as it was freeing ourselves from commitments we no longer wanted."

In setting out the course for transition, MSU's senior management committed themselves to several goals. The first goal was an explicit policy to buy commercial software and not build any more systems in-house. They then partnered with two leading enterprise systems vendors to provide products encompassing the most critical functions. They also installed smaller, niche, packages from more than a dozen vendors.

The technology leaders at MSU also chose to retrain existing technical personnel instead of attempting to replace them. This led to a situation where more than $80 \%$ of the preimplementation staff are still part of the information systems group at MSU. The CIO and his senior managers also wanted to rely on minimal external consulting. So, while the industry average for implementing enterprise computing systems is about $\$ 3$ to $\$ 5$ of consulting for $\$ 1$ of software, MSU has maintained about a $\$ 2: \$ 1$ ratio over the current life of the project (Bond, Keller, \& Block, 1995; Swartz \& Orgill, 2001). 
A third goal was to decentralize the support of the information technologies being implemented. This had two aspects. The first aspect was that MSU's central information technology group promoted extensive user involvement, and more than 100 committees were formed to assist in implementing the new distributed computing systems. Most of these committees were led by line, not technology, people. A second aspect of the decentralization of the technologists was the creation of a distributed technical staff program. These distributed technical staff positions were funded jointly by a central information technology group and participating units at MSU. These distributed technical staff serve as network managers, troubleshooters, trainers, and local computer "gurus." (i.e., Eschenfelder, Heckman, \& Sawyer, 1998). Finally, when they embarked on this transition in 1993, the CIO and his staff were aware that many of the client/ server-based products they needed to improve the current computing infrastructure were not yet available. So they expected to see the plan change to meet the needs of both the institution and the software/hardware products markets.

The MSU enterprise implementation was conceived as a multiproject effort, and major milestones in the project are outlined in Table 2. The order and priority of these projects was defined by negotiating among key stakehold ers such as senior line managers, technology vendors, executive leaders, and internal technologists. The criteria that helped to structure these negotiations included user/functional needs, availability of needed software, political gain, and resources. Thus, the temporal pacing of the project varied. Sometimes the organization's functional needs were not met by available software products. For instance, an early unmet need was for a cross-platform and cross-product security application that would allow users a "single-sign-on" access path. Such a product was needed in early 1995, and no suitable application came onto the market until 1997. A second example of the way priorities changed was the revamping of the project schedule to reflect the additional resource demands of the Year 2000 remediation effort. When the implementation plan was first conceived, it was to complete in 4 years. However, as the implementation continued, it became necessary to remediate (and not just replace) existing (and not Year 2000-compliant) applications. Simply, in almost every project action, time was a factor in decision making.

We viewed the situation at MSU to be especially favorable for studying organizational change in the context of an enterprise systems implementation. Two reasons were salient. First, when we began the research, MSU was still in the relatively early stages of its multiyear implementation. Thus, we were presented with the opportunity to follow the project from the planning/design phase of implementation (preinstallation) through the eventual, actual use of the technology (post-installation). Second, the scope of the implementation effort was organizationwide. The project called for a complete transition from the existing mainframe-dominated architecture to a client/ server architecture, where the transition was targeted to span several years. In order to reach this objective, the implementation project plan established many smaller department-specific projects (e.g., admissions, financial aid, etc.). This multiproject structure allowed us opportunities for research involving multiple levels of analysisboth within the organization and across organizational boundaries (e.g., their relationship with technology vendors and implementation consultants).

\section{Data Collection and Analysis}

In this article we take a project (not user) perspective and focus on the collective effort of MSU's people to implement (by which we mean here to install and make run the functionality of) the enterprise system. Assessing the effects of the enterprise systems and the implementation process is beyond the scope of this article.

Data collection activities centered on participation with, and observations of, committees formed to work on specific aspects of the implementation effort along with interviews with managers and workers (both technologists and line staff). Interviews varied by level of structure, with most being semistructure d and open ended. Interviewees were asked if they minded being taped; if they were reluctant, we did not tape the interview. We develope d two types of field notes for each observation, interview, or interaction. The first type is a chronology of events and actions; the second is a more free-flowing account of perceptions, stories, and anecdotes. The chronology serves as a record of observations. The account serves as a record of the observer's perceptions. We also had access to formal documents and the archives of the implementation (including e-mail, work records, project management plans, memos, and reports).

Data collection was designed to allow for individual and organizational levels of analysis. At both levels, we focused on the temporal aspects of implementing the enterprise system. In doing this, we focused on understanding the potentially differing temporal perspectives among users, technologists, and vendors. Data for analysis include more than 300 hours of meetings, 120 interview s (averaging about $65 \mathrm{~min}$ each), 12 focus groups (with 5 to 10 attendees), and nearly 1000 documents (e-mail, memos, handouts, and reports).

Five people participated in data collection, and two were part of the project from its inception. Data were 
TABLE 2

MSU's ES implementation timeline

1993

1994

1995

1996

1997

1998

1999

2000

2001

Expected schedule:

2001

2002
New CIO appointed (asked to develop strategic computing plan for MSU)

Five-year plan for client/server infrastructure and enterprise systems effort

Decentralization of computing support staff begun

Information systems manager (in charge of implementing enterprise system) hired

Initial client/server infrastructure change initiated (cabling and network components)

Departmental desktop computing standards promulgated

(this is a standard/minimum hardware and software configuration for computers/networks/servers)

Enterprise software vendor chosen and initial implementation plan developed into five main modules:

1. Endowments and giving (separate vendor for this, same vendor for the other four, below)

2. Student record/registration and admissions

3. Human resources and payroll

4. Student financing

5. Finance (including accounts payable/accounts receivable)

First enterprise system vendor fails/folds

Basic client/server infrastructure in place

First (small) client/server application installed (postimplementation problems with operation)

Second enterprise systems vendor selected (runner up to first-choice selection that folded)

Departmental desktop computing standards revised (upgrades needed)

First information systems manager steps out of this role (voluntarily)

Endowments application "up" (requires migrating 500,000 records)

Student record/registration and admissions module "up" (requires migrating 700,000 records)

Y2K remediation needed (due to project delays)

Decision made to move finance up in schedule to be third major module

Human resources and payroll module implementation fails

MSU hires specialized consulting firm to oversee reimplementation of this module

(specialized means here that the firm is often hired to oversee implementation of a failed first effort)

Departmental desktop computing standards revised again (upgrades needed)

Second information systems manager steps out of the role (voluntarily)

Human resources and payroll module implemented

Finance module implemented

External information systems auditor brought in to evaluate project process and outcomes

(receive a generally positive evaluation)

Begin to implement some online commerce functionality for procurement

(building on newly implemented finance/accounts payable/receivable functionality)

Creation of internal process reengineering department.

Process change efforts initiated in areas where first two modules are operational

Departmental desktop computing standards revised (upgrades needed)

Student financing module to be "up" in fourth quarter.

Enterprise systems installation to end (though process changes will continue) collected from 1994 through early 2001. We began 6 years of fieldwork with a 10-month period of gaining access to, and the confidence of, the site's employees. In the process of coordinating and tracking the data collection effort, we have used vignettes and stories to help develop a shared understanding of what we are observing (e.g., Miles, 1979, 1990). Through this planned-but informal-interim effort, several themes emerged. These themes have been used to return to the field notes and organize data to support or refute their value. This was done using explanatory event matrices (Miles \& Huberman, 1994; Miller \& Friesen, 1980). These results are summarized in the right-hand columns of Table 1 and discussed later. 


\section{Specific Implementation Characteristics at MSU}

At MSU there is evidence of all three specific implementation characteristics. For example, the increased number of stakeholders and stakeholder groups is a central feature of the MSU effort. During this transition, more than 15 implementation project teams were involved with 14 different software packages. This effort led to nearly 100 committees involving nearly 700 people. These committees comprised technologists, users, and often vendors and/or consultants. Committees existed at both executive levels (steering committees) and line levels (customer action teams) in the organization. Typically they were led by a nontechnologis $t$ and comprised from 5 to 15 people. Any particlar software package implementation project had as many as 20 committees, with many people sitting on multiple committees. This is the essence of large-scale organizational change: the extensive involvement of many people (Benjamin \& Levinson, 1987; Liker, Roitman, \& Roskies, 1987; Markus \& Benjamin, 1997). One role of the enterprise technologies is thus an "occasion to structure" (Barley, 1986) as the implementation project is laid over the existing organizational hierarchy.

A second characteristic of the implementation is the presence of multiple effects at multiple levels in the organization. In essence, MSU's enterprise systems implementation effort involves many people who are struggling to maintain a stable, productive state even as their world is changing. One example of the multiplicity of forces is the stress on project management. Despite the techniques and instruments used by the IS department in its attempt to invoke or impose a temporally defined order for internal development efforts (such as PERT and Gantt charts), the actual client/server project at MSU is far from controllable. There are two reasons for this. The first is that control of implementation/development schedules is now split three ways, with increased control by the vendors and the users coming at the expense of the technologists' control (see also Sawyer, 2001). While the technologists retain some control, such as access to key technical personnel and the right to dictate some technical issues, the functional characteristic s (and delivery dates) are mainly subject to vendor timelines.

Likewise, implementation of these functions is dictated by user schedules. At MSU the most complex (in terms of multiple user groups being involved) system being implemented is in support of student records, as it includes admissions, financial aid, the bursar, and the registrar. Since each of these departments operates on a different schedule (admissions is busy in late spring, the bursar in the summer and fall, etc.), there is no "convenient" time to roll out an integrated package. A second example reflects MSU's Year 2000 remediation. In part, the enterprise system implementation was being done to obviate the need to do Year 2000 remediation on legacy systems. However, vendor-provided software was not available for several functions and MSU had to take on the added work of fixing (not replacing) legacy systems. This led to a point where the MSU technologists were negotiating three sets of time schedules: software vendors, current users of the legacy systems, and their own needs and resource constraints.

Most technology implementation projects face schedule changes, given the number and interdependencie s among the resources, tasks and schedules. However, the most insidious aspects of the frequent schedule changes reflect the limitations of linear estimates of projects to account for the polychronicity of work. Many of the project team members (if not all) are tasked to multiple committees, with each of these efforts proceeding at differential rates. The temporal costs of these people's increased cognitive load due to task switching is not accounted for in these plans. That is, as work pressures increase, people's cognitive processes (ability to switch among tasks, to take in signals from the environment, to negotiate priorities, and to even maintain civility ) suffer (Woods \& Patterson, 2001). Simply, people are not as efficient or effective if there is too much to do per unit time.

There is also evidence from the MSU study supporting our contention that environmental constraints affect temporal perceptions. Evidence for this draws on incidents such as the technology leadership's responses to their Year 2000 problem. When they began the transition to client/server computing, planning assumption s were based on completing the transition prior to the millennium. Because of vendor problems - their first vendor could not deliver as needed - the MSU leadership switched to a second vendor. This change forced MSU to fall behind its implementation schedule and it had to become very concerned about Year 2000 issues. Thus, as we alluded to earlier, instead of being a nonissue, dealing with the Year 2000 dominated the MSU technology leader's planning as they needed to trade off resources to either repair current legacy systems or speed up the implementation. Both led to a sense that time is "short." This, in turn, led to rushed decision making and a sense of constant crisis. This type of self-reinforcing "time famine" has been documented in software development (see Perlow, 1999), and we see evidence of that at MSU.

\section{Features of the Enterprise Systems Technologies at MSU}

There is also evidence of the three features of enterprise systems in MSU's implementation effort. For example, the combination of the enterprise software's immaturity and the dependencies among, and between, the technologies and the stakeholders make possible many starts, stops, 
and redirections in the implementation effort. For instance, specific functions were often not available in the enterprise software's current version when the people at MSU needed them. Two examples from the data showcase this feature. The first case is that the MSU technology managers predicated their original project plan on having key student processing functions available by fall 1997. However, there were no viable products when they looked at the market in 1994. After that, the two dominant players moved in different directions. The vender MSU first chose fell behind schedule and subsequently bought out its contract. This forced MSU to negotiate a contract with the second vendor 3 years into the installation effort. A second case is the search for a reasonably priced security package that will provide single-entry passwords to multiple applications, described earlier.

These two examples illustrate how the development and deployment of the computing infrastructure on which the enterprise system resides can proceed in fits and starts, with numerous changes in direction, rather than following a linear path of gradual and steady progress. MSU's project plans, and most deadlines, are flexible (and often not met). These plans are steadily revised to account for which products are ready and what sequence of dependencies among projects can be met. While this makes sense at a strategic level, users translate this differently. Users see this as poor leadership and thus discount plans produced by the technologists and vendors (since internal information systems staff intermediates the vendor-user links). This puts the internal information systems staff in a unique place-they know how hard it is to plan, yet they must act as overseers to vendors and as advocates for users. At the same time they often serve as apologists for the vendors. The CIO, after visiting the senior management of one enterprise systems vendor whose product was very late, said, "I'm sick of being their whipping boy."

Many factors-internal and external to the organization-may contribute to either stimulate, retard, or even derail the development of the enterprise software. For example, software upgrades in this environment are frequent. One project had a new update to its software about every 3 weeks. From the vendor's perspective, it was developing software at breakneck speed and being responsive. The users interpreted this pace as sloppy development which created a churning feeling. The lead implementor for the system called it "computing on roller skates."

In large part due to the need for the technical interoperability that the composite computing infrastructure relies on, there is a fast-paced, continuous process of software development and redesign to fulfill the promise of enterprise systems. Each new product necessitates modifications (or replacements) to existing components, making this a seemingly self-perpetuating process. The breadth of innovation is accentuated by the fact that the concept of a computing network, especially in a technical sense, now commonly transcends organizational boundaries. The interest in Internet technology has widened the scope of interoperability. In turn, this has also contribute d to accelerating the pace of product innovation.

While this situation may not be unique or surprising, given the fast-moving state of client/server and Internetworking technologies, the composite nature of the infrastructure in this form of computing compounds the problem. Our observation s to date suggest that, at this stage in the technological evolution, the transition from mainframe computing to distribute d computing will continue to be challenging for all groups and individuals involved with the implementation project at MSU because of the system's complexity. This has been especially evident in the meetings of oversight committees, where progress on individual subprojects appears to be continually undermined by the necessity to devote time to solve technical problems. For example, the director of the implementation says of the weekly technology directors' meeting: "I'm not comfortable, yet, with the directors. People talk about the technology, they talk about the budgets, they talk about the dynamics of [our group]. We never talk about the transition [the set of projects that are implementing the client/server systems]." The information center manager says: "We don't plan, we don't pay much attention to anything but the new technology. [We] never talk about how to use [the new software systems]."

Moreover, the distribute d nature of client/server computing, which underlies the systems at MSU (as it does most contemporary enterprise systems), applies to the social structure of the organization, not just to the spatial configuration of the physical technology (Wellman et al., 1996; Wellman, 2001). That is, distributed computing, on which the enterprise systems runs, enable a greater degree of freedom for technical independence within organizational subunits. Individual departments within MSU are adopting different strategies for computing, such as using Windows NT instead of Novell as the network operating system. This makes it more difficult for the technologists, who are attempting to coordinate the computing infrastructure, to maintain a sense of control over it. As the director of the physical network states: "In some sense, [this is] the most strategic decision we made [i.e., allowing a department to break from the standard network configuration]."

\section{DISCUSSION}

In this part we move beyond the findings regarding specific implementation issues and aspects of the enterprise systems to focus on what the findings might mean. We begin by discussing temporal asymmetries among groups and then discuss the increased polychronicity of work. 


\section{Temporal Asymmetries Among Groups}

In light of the near-frenzied pace of innovation in both enterprise systems and distribute d computing, it becomes an even more daunting challenge for any organization to stay abreast of such technical change, and, consequently, to maintain technical integrity (interoperability) among the various segments of the broader organizational infrastructure. Simply, it is difficult to entrain the technologyembodied in these systems - with the work practices of the organization (Ancona \& Chong, 1996). This accelerating pace sets the stage for temporal asymmetries to exist among vendors, users, and technologists .

Technological developments have forced MSU's information systems staff to shift their focus from mainframe to client/server computing, and the technological staff struggles to comprehend the new technologies. Vendors, who have embraced the client/server as the architecture for their enterprise products, are positione $d$ to respond to these technological developments more easily than the information system's staff at MSU. Users are the least able to keep pace with these technological changes, and this creates the potential for intergroup conflicts that arise from temporal asymmetries.

For example, in speaking with various managers and administrators within MSU, we heard repeated reference to fall 1997 as the (missed) target date for a complete transition from the mainframe system to a client/server computing system. This was the date originally set (in 1992) by the CIO to coincide with the termination of agreements with mainframe contractors. Because of the changes in enterprise vendor (and other issues), by early 1996 this date had been changed (to 1999). However, the original date continued to be used as a measure by many of the line departments. The temporal asymmetry that we perceive exists between those who are most actively involved in the transition and those who are not. The former saw 1997 as a "drop-dead" date. The latter saw this date as unreachable and thus flexible. Since this dichotomy was never explicitly discussed, it gave rise to conflicts over the importance of different projects (order, deadline dates).

Further, we note the potential for temporal asymmetry to persist between developers and users. This may have the effect of leading to inaccurate decisions in the users' evaluation of systems, since perceptions of development time are structured according to traditional development cycles, rather than the rapid pace of enterprise software and client/server development. For instance, one vendor, who at that time had no product available, was selected over another, who had a product that was considered "buggy" or mistake filled, because of a strong perception that this vendor was further along in the development cycle. The second vendor argued that "it is the nature of client/server in its present state that learning takes place through implementation." As we noted earlier, within 3 years of this decision, the first vendor was out of business and MSU was forced to sign a less flexible contract with the second vendor.

We further extend this argument to suggest that the temporal asymmetries between developers and users leads to an unprecedented degree of control by developers over users (e.g., Markus, 1983; Kling \& Iacono, 1984). Related to this point is that the user may maintain the perception that the length of time it is involved with a vendor is indicative of the degree of development of a product. In other words, it perceives a process that is linear and cumulative when the process is, in fact, discontinuou s and constantly reinitiated.

Because of the volatility of innovation in enterprise technologies, many applications persist in beta form. Weick (1990) has previously suggested that "new technologies" follow a pattern of development different from that of older technologies. The high level of mental interpretation and subsequent uncertainty in knowledge of the process serve to result in a situation in which "implementation often is the means by which the technology itself is designed" (Weick, 1990, p. 8). We see this as an emerging standard for distributed computing. Beta versions of software are often the norm with upgrades occurring in beta-stage applications. As we noted earlier, one of the vendors providing software for MSU released a new version every few weeks. This sets the stage for temporal asymmetries to persist.

\section{The Increased Polychronicity of Work}

The temporal aspects of individual work are being affected in two ways: how workers view the tasks they do, and how they interact with each other. That is, the subjective nature of time affects both the tasks and the people. The MSU technologists' tasks, for example, are more interdependent, have higher levels of visibility, greater variety, and less autonomy in selection (that is, often they must respond to what others have done), and demand a broader variety of skills to complete. This is a difficult adjustment for many, since they had become familiar with the relative simplicity (and monochronicity) of supporting a stable (mainframe) technology.

These technologists are also responsible for more tasks. Since the tasks demand new ways of sequencing and are more interconnected, workers are participating in more task sharing. This is where many people contribute to completing one task. Thus, the workers' days are often more fragmented as they constantly connect with others to complete these shared tasks.

The combination of these two makes the knowledge worker's work day seem chaotic. For instance, one 
technologist was given the task of maintaining the access tables for all distributed applications. This requires maintaining a number of access tables, since, as we noted earlier, no single-sign-on security product was available at the time. When she went on vacation, no one could get access to a number of applications (for a small technical reason). Here, the monochronic logic of one person, one task, broke down in the face of polychronic work. Another example of this polychronicity - using the same example - is that she complained to us about how hard it was to maintain these different access tables, even though it was roughly the same task across a number of applications. The constant balancing of several applications' security tables was much different from her previous monochronic work supporting one system.

The enterprise systems, and the pervasive distribution of computing, at MSU means that work is less monochronic and more polychronic (Barley, 1988; Bluedorn, Kaufman, \& Lane, 1992; Vinton, 1992). In polychronic work, workers are expected to be able to switch among multiple tasks, while monochronic work is focused on sequential task completion. This synchronicity affects how people experience time. For example, one of the most frequent comments we have heard in our interviews and observation is that people have too many things to do. This leads to a perception that they lack time. And, while people are reasonably bad at recalling how they spend their work time (e.g., Hartley et al., 1977), disruption s to temporal patterns are very dislocating to many of the users and technologist s (Perlow, 1999; Woods \& Patterson, 2001).

\section{IMPLICATIONS}

In this final part we reflect on several implication s of this temporal perspective. We begin by briefly returning to professional issues and highlight how the use of current project management tools leads to some unintended temporal consequences. Then we discuss the value of a temporal perspective as a conceptual lens for researchers, focusing on the role of the time in both framing the analysis and helping us to examine the relationship s among information and communication technologies and social organization.

\section{Time as a Barrier to Managers}

We began this article by noting that managers are often aware, at least implicitly, of the dual nature of time. Through the course of the paper we have pointed out that contemporary project management tools are premised on linear time. This leads to a paradox where most project managers are aware of the limitations of the tools but are not sure why that is so, or how to reflect this in their management. This is, we posit, a major contributing factor to the inability to manage most ES implementation projects in a rationalized way. The unintended consequence of this is that managers learn to trust their instincts, not their tools of control, without understanding why that is so. However, people often poorly estimate how they spend their time (e.g., Robinson \& Godbey, 1997); this is particularly true in work environments (Hartley et al., 1977). This suggests that while a linear view of project process is flawed, a perceptual approach to scheduling may be no better: Temporal instincts serve managers well in many ways, but not with scheduling. Perhaps this helps to explain why many projects fall into the "90\% complete" trap-where this perceived level of completion is "attained" ahead of the estimated schedule, while the last $10 \%$ is difficult to reach (Abdel-Hamid, 1988). The observations from our work suggest that project management scheduling demands a more discipline d approach: The important adaptation is to measure perceived progress along with calendar/task progress. When these two measures begin to diverge, this can be addressed. Imagine two time scales on a Gantt or PERT chart: linear and perceived. In this way it is easier to see a temporal discrepancy occuring: It begins when the two time scales diverge on a particular task.

\section{Time as a Lens for Researchers}

We conceptualized organizational change as a situated event: It occurs in specific times at specific places (Orlikowski, 1996; Suchman, 1987). Temporal issue s help to situate these events, especially the pervasive and deeprooted effects that large-scale technology changes such as enterprise system implementation s demand. The stressful social milieu that arises from organizational change brings together, and often exposes, the differences in the social norms and values around the time when these different groups attribute to events and to artifacts. The subsequent temporal asymmetries among groups are often difficult to perceive due to the objectification of time's measurement (Schein, 1992; Hall, 1959).

Gersick (1988, 1989, 1991; Gersick and Hackman, $1990)$ addressed the nonlinear and nonhomogeneou s nature of time as it affects group decision making and problem solving. Applying a metaphor that arose in natural science (Eldredge \& Gould, 1972), Gersick advances a model of "punctuated equilibrium" for group-level theory to explain the discontinuous, and apparently spontaneous, patterns and pace of activity exhibite in the course of group development projects. The punctuated equilibrium model differs from other models of group and industry-wide activity in which processes are assumed to be linear and incrementally additive (Gersick, 1989; Tushman, Newman, \& Romanelli, 1986; Romanelli \& Tushman, 1994).

Gersick's model straddles the dual conception s of time and reflects both objective and subjective (socially constructed) time. Using punctuated equilibria theory, we 
would posit that, given a fixed end date, a social unit—such as a work group-begins to work toward the shared goal. As the work group reaches the chronological midpoint, a crisis ensues. This crisis leads to a redirection of effort toward meeting the goals by the prespecified and fixed end date. A final, eleventh-hour supereffort completes the process and the goal is reached at the deadline.

However, punctuated equilibria theory relies on both clear goals and a fixed end date, from which interim stages and direction s can be assessed. Given the amorphous temporal nature of an enterprise system implementation and the uncertain end dates of most information technology projects, it is possible that a midpoint crisis results in both a redirection and a new end date being established. Given a new end date, a new midway point is established, and a new crisis is then likely. Thus, without a fixed end date, punctuated equilibrium theory implies an eerily common pattern of crises, redirections, and moving end dates for enterprise systems implementations. Certainly the (oft) extended project completion date at MSU and the annual set of crises and redirects surrounding these extensions provide some support for this hypothesis. This suggests the need for additional research to ascertain the temporal aspects of controlled project end dates and project success.

The increased interdependence and number of stakeholders, along with the myriad and dynamic technical features of client/server-based enterprise systems, are the context in which implementation plays out across time. This suggests that the implications of temporality can be best understood in the field and not in an environment controlled by the researcher (McGrath, 1986, 1988, 1991; Futoran, Kelly, \& McGrath, 1989). This, in turn, encourages observations and interviews across objective time as the basis of research on information systems implementation. However, while the employment of longitudinal research methods may be assumed to provide such an accounting, it may do so only in a limited way unless it is theoretically specified by the researchers prior to data collection (Monge, 1990).

Longitudinal methods may follow dynamic processes across time, rather than take snapshots, but do not necessarily incorporate a theoretic basis for time (Robinson \& Godbey, 1997). Most social scientists see time in the Newtonian sense; metaphorically represented as an "arrow," imposing a linear order or sequence on events (Dubinskas, 1988, p. 7):

Many social scientists have rather uncritically incorporated this orderly time of Newton into their own models, treating time as a background or hidden dimension. It becomes an attribute of the natural universe that is simply there (or "ticking away") as a parameter, marker, or line against which events and activities unfold in an orderly fashion and are then measured by the analyst.
Such an interpretation fails to account for time as a socially constructed phenomenon. So, longitudinal methods allow, but do not demand, the researcher to understand the subjective nuance of time in context (Croissant, 1998). Our experience with subjective aspects of time, in the context of the MSU enterprise systems implementation study, helps to illustrate how a broader view of time can assist understanding. Were we to take a strictly linear and objective view of time, the inability of MSU's technologists to meet many of their target dates would seem to be a failure in project management.

Assessing these same instances of missed project deadlines from a perspective that allows for the force of temporal asymmetries to shape action suggests that the issue in play is not the deadline date. Instead, the issue is about negotiating a more comfortable pace of change (i.e., Baronas \& Louis, 1988). That is, user groups desired more control over when that date should be and drew on factors other than technical availability of the product to inform that decision. The temporal perspective also allows us to look beyond the seemingly erratic behavior of the technologists, who both embrace the changes to their work and struggle with the way their work changes force them to be more temporally interdependent.

These observations on time suggest that researchers must explicitly account for both objective and subjective time in data collection. We believe that a primary, but underdeveloped, power of longitudinal research is the opportunity to focus on the subjective aspects of time. Evidence of time's subjective nature arises from analyzing the data from a temporal perspective, from understanding the broader context, and from comparing narratives and observations across perspectives and levels of analysis. A temporal perspective can be better enabled by further modifying data collection efforts in two ways. The first way is to account for the subjective time lines of the various constituents. The second way is to explicitly record perceptions of temporal asymmetries as part of the field notes following each observation.

We used the two forms of chronology to provide contrast. The calendar-based (objective) timeline was the basis for mapping the perceived pace of deadlines by noting whether people felt they had enough (or too little) time. This gave us insight into how various groups assessed the pace of implementation. It also allowed us to see more clearly the existence of temporal asymmetries among groups. It also provided a means to relate the number of issues at play in a given time period. This provided a means to assess the relative polychronicity of various work groups (by counting up the number of concurrent issues and or project deadlines per period).

This approach to data collection suggests a need for some comparative and/or evaluative temporal frameworks (e.g., Perlow, 1999; Abbott, 1995) related to information 
systems uses. One such framework is Lee's (1999) six dimensions of temporality relative to business processes. In this framework, duration is the amount of time spent to complete a task or an activity. Temporal location refers to the location of activities and tasks at particular points over the continuum of time that they take place. Sequence is the order in which activities and tasks take place. Deadline is the fixed time by when work is to be done. Cycle is the periodic regularity in which work is completed repeatedly. Rhythm is the alternation in the intensity of being busy. Lee (1999) demonstrates the use of this model to analyze the changes in work due to the introduction of an EDI trading system.

\section{Time and the Sociotechnical Worlds of Enterprise Systems}

We began the MSU study believing it was necessary to incorporate the rules, norms, values, and even the subjective perceptions of the people involved, not just the physical attributes of the system, in order to reach an understanding of the ways enterprise system (a specific form of the more general construct of technology) can enable organizational changes. Through this article we have developed that an enterprise system-which is often seen as discrete pieces of hardware and software-is intimately embedded in a socio-technical ensemble (Bijker, 1995; Fleck, 1994; Orlikowski \& Iacono, 2001).

The enterprise system becomes the embodiment of the technical aspects of an organization's computing infrastructure. This infrastructure gives rise to and also reflects norms of behaviors and artifacts of action-it is as social as it is technical. A temporal perspective provides additional insight into the sociocultural and administrative aspects of this socio-technical system. Our study to date has reaffirmed this definition of technology, extending the concept of an enterprise system to the broader concept of computing infrastructure, connecting time to (information and communication) technology as elements or manifestation of sociotechnical life (Bijker, 1995; Latour, 1988; McGrath, 1988; Young, 1988; Lee, 1999).

Further, new computing technologies, represented by client/server-based enterprise system s in our work, present significant obstacles to understanding the effects of computing infrastructures on organizations because they are so configurable and pervasive. This is true for the designers and users of these systems and for organizational researchers. One recurrent question is, "How will we know whether the impacts on the organization are caused by the client/server or software elements of the technology?" The present findings suggest the irrelevance of such questions that imply a causal relationship between technology and organizational change (i.e., the technological imperativesee Markus \& Robey, 1988).
The world of distributed computing, and enterprise systems in particular, is a world of metaphors - clients, servers, tiers, data warehouses, and icons. These systems are not singular or uniquely distinguishable technologies; witness the difficulty one encounters in trying to obtain a consensus regarding its definition. For instance, when asked, one manager responded that client/server is "just one more icon on my screen." Client/server seems to be an inclusive phrase that accommodates a wide range of companion technologies with a working assumption that it is possible to get these wide-ranging elements to work together. Likewise, enterprise system is a broad term that intimates a breadth of software functionality and integration that is both fluid and expanding. The power and value of these inclusive terms are constrained by the inability to say what they actually mean, since they are often discussed out of the sociotechnical context of their use.

As we have argued, the topicality of enterprise technology implementations both masks and highlights the dual nature of time. The enormous investments in these systems, their pervasive distribution, the variations in potential power at the hands of the users, and the multitude of different product timelines that, combined, represent the aggregated development trajectory of any distributed computing infrastructure provide a milieu for observing temporal asymmetries among the various constituents. A temporal perspective provides insights into how the sociotechnical nature of enterprise systems, and perhaps of any information technology implementation, is set in the context of time. Given the socially shaped nature that a temporal perspective implies, this suggests the selflimiting nature of a simple chronological view of time (Bijker, 1995; Zuboff, 1988).

One aspect of a temporal perspective that we did not explore in this research is the entrained relationship between technology development and organizational implementation. By entrainment we mean the changes in pace or cycle of an activity to match or synchronize with another activity (Ancona \& Chong, 1996, p. 253). For example, as software development is increasingly done by specialized firms, the issues with the entrainment between producer's cycles of development and consumer's cycles of implementation become critical (Sawyer, 2001; Fleck, 1994).

The aspects of a temporal perspective explored in this article-polychronicity and asymmetry-provide insight into individual and group-level behaviors beyond what a simple clock-time perspective could provide. The current work establishes how enterprise computing is involved in the organizational change that defines an implementation. To provide a temporal frame for this, we began a chronology, tying events to a calendar to help organize and interpret them. This has helped us to understand how time's multiple roles magnify change related to information systems implementations. For us, the differences in 
how people see time have arisen from attempts to see the world through their eyes, and this is the essence of the interpretive approach we have taken.

\section{REFERENCES}

Abbot, A. 1995. Sequence analysis: New methods for old ideas. Annual Review of Sociology 21:93-113.

Abdel-Hamid, T. 1988. Understanding the "90\% syndrome" in software project management: A simulation-based case study. Journal of Systems and Software 8(1):319-330.

Alpert, D. 1985. Performance and paralysis: The organizational context of the American research university. Journal of Higher Education 56(3):242-281.

Ancona, D., and Chong, C. 1996. Entrainment: Pace, cycle and rhythm in organizational behavior. Research in organizational behavior 18:251-284.

Avital, M. 2000. Dealing with time in social inquiry: A tension between method and lived experience. Organization Science 10(6):665-673.

Barley, S. 1986. Technology as an occasion for structuring: Evidence from observations of CT scanners and the social order of radiology departments. Administrative Science Quarterly 31:78-108.

Barley, S. 1988. On technology, time and social order: Technically induced change in the temporal organization of radiological work. In Making time: Ethnographies of high-technology organizations, ed. Frank A. Dubinskas, pp. 123-169. Philadelphia: Temple University Press.

Barley, S. 1990. Images of imaging: Notes on doing longitudinal fieldwork. Organization Science 1(3):220-249.

Baronas A., and Louis, M. 1988. Restoring a sense of control during implementation: How user involvement leads to systems acceptance. MIS Quarterly 12(1):111-124.

Beckhard, R., and Harris, R. 1987. Organizational transitions: Managing complex change. Reading, MA: Addison-Wesley.

Benjamin, R., and Levinson, E. 1993. A framework for managing ITenabled change. Sloan Management Review 34(4):8-18.

Bijker, W. 1995. Of bicycles, Bakelites and bulbs: Toward a theory of sociotechnical change. Cambridge, MA: MIT Press.

Bluedorn, A. 2000. Time and organizational culture. In Handbook of organizational culture and climate, eds. N. Ashkanasy, C. Wilderon, and M. Peterson, pp. 231-267. Thousand Oaks, CA: Sage.

Bluedorn, A., and Denhardt, R. 1988. Time in organizations. Journal of Management 14:299-320.

Bluedorn, A., Kaufman, C., and Lane, P. 1992. How many things do you like to do at once? An introduction to monochronic and polychronic time. Academy of Management Executive 6(2):17-26.

Bond, B., Keller, E., and Block, J. 1995. ERP vendor guide 1995, Part 1. Gartner Analytics Report R-345-120, Boston, MA.

Brooks, F. 1974. The mythical man-month: Essays on software engineering. Reading, MA: Addison-Wesley.

Brown, J., and Duguid, P. 1991. Organizational learning and communities of practice. Organizational Science 2(1):40-57.

Brown, S., and Eisenhardt, K. 1997. The art of continuous changes: Linking complexity theory and time-paced evolution in relentlessly shifting organizations. Administrative Science Quarterly 42:1-34.

Brynjolfsson, E. 1994. Information assets, technology, and organizations. Management Science 40(12):1643-1662.
Bucciarelli, L. 1988. Engineering design process. In Making time: Ethnographies of high-technology organizations, ed. F. Dubinskas, pp. 92-122. Philadelphia: Temple University Press.

Burkhardt, M. 1994. Social interaction effects following a technological change: A longitudinal investigation. Academy of Management Journal 37(4):869-898.

Carmel, E., and Sawyer, S. 1998. Packaged software development teams: What makes them different? Information Technology and People 11(1):7-19.

Croissant, J. 1998. Criteria for a theory of knowledge. In What is social theory: The philosophical debates, ed. A. Sica, pp. 145-172. Malden, MA: Blackwell.

Dubinskas, F. 1988. Cultural constructions: The many faces of time. In Making time: Ethnographies of high-technology organizations, ed. F. A. Dubinskas, pp. 3-38. Philadelphia: Temple University Press.

Eldredge, N., and Gould, S. 1972. Punctuated equilibria: An alternative to phyletic gradualism. In Models in paleobiology, ed. T. Schopf, pp. 82-115. San Francisco, CA: Freeman, Cooper.

El-Khawis, E. 1995. Campus trends: 1995. In Higher Education Panel Report, Number 85, pp. 13-21. Washington, DC: American Council on Education.

Eschenfelder, K., Heckman, R., and Sawyer, S. 1998. "The distribution of computing: The knowledge markets of distributed technical support specialists. Information Technology and People 11(2):84103.

Failla, A., and Bagnara, S. 1992. Information technology, decision, time. Social Science Information 31(4):669-681.

Fleck, J. 1994. Learning by trying: The implementation of configurational technology. Research Policy 23:637-651.

Forrester Research. 1998. Sizing commerce software. Boston, MA.

Francalanci, C. 2001. Predicting the implemention efforts of ERP projects: Empirical evidence on SAP/R3. Journal of Information Technology 16(1):33-48.

Friedman, J. 1990. About time. Cambridge, MA: MIT Press.

Futoran, G., Kelly, J., and McGrath, J. 1989. TEMPO: A time-based system for analysis of group interaction process. Basic and Applied Social Psychology 10(3):211-232.

Gersick, C. 1988. Time and transition in work teams: Toward a new model of group development. Academy of Management Journal 31:9-41.

Gersick, C. 1989. Marking time: Predictable transitions in task groups. Academy of Management Journal 32(2):274-309.

Gersick, C. 1991. Revolutionary change theories: A mutlilevel exploration of the punctuated equilibrium paradigm. Academy of Management Review 16(1):10-36.

Gersick, C., and Hackman, J. 1990. Habitual routines in taskperforming groups. Organizational Behavior and Human Decision Processes 47:65-97.

Golden-Biddle, K., and Locke, K. 1993. Appealing work: How ethnographic texts convince. Organization Science 4(1):595-616.

Hall, E. 1959. The silent language. New York: Anchor Books.

Hammer, M. 1999. Up The ERP revolution. Information Week, http://www. techweb.com/se/directlink . cgi ? IWK19990208S007 6 (accessed March 17, 1999).

Hartley, C., Brecht, M., Pagerey, P., Weeks, G., Chapanis, A., and Hoecker, D. 1977. Subjective time estimates of work tasks by office workers. Journal of Occupational Psychology 50:23-36. 
Hassard, J. 1996. Images of time in work and organization. In Handbook of organization studies, eds. S. R. Clegg, C. Hardy, and W. R. Nord, pp. 581-598. London: Sage.

Hirschheim, R., Klein, H., and Newman, M. 1991. Information systems development as social action: Theoretical perspective and practice. OMEGA International Journal of Management Science 19(6):587608.

Jones, J. 1988. Cultural differences in temporal perspectives: Instrumental and expressive behaviors in time. In The social psychology of time: New perspectives, ed. J. McGrath, pp. 21-38. Newbury Park, CA: Sage.

Keil, M., and Carmel, E. 1995. Customer-developer links in software development. Communications of the ACM 38(5):33-44.

Kelly, J., and McGrath, J. 1988. On Time and Method. Newbury Park: Sage Publications.

Kling, R. 1992. Behind the terminal: The critical role of computing infrastructure in effective information systems' development and use. In Challenges and strategies for research in systems development, eds. W. Cotterman and J. Senn, pp. 153-201. London: John Wiley and Sons.

Kling, R., and Iacono, S. 1984. Computing as an occasion for social control. Journal of Social Issues 40(3):77-96.

Kling, R., and Scacchi, W. 1982. The web of computing: Computing technology as social organization. Advances in Computers 21:1-90.

Latour, B. 1988. Science in action. How to follow scientists and engineers through society. Cambridge, MA: Harvard University Press.

Lee, H. 1999. Time and information technology: Monochronicity, polychronicity and temporal symmetry. European Journal of Information Systems 8(1):16-26.

Lee, H., and Liebenau, J. 2000. Time in organizational studies: Towards a new research direction. Organization Studies 20(2):1035-1058.

Liker, J., Roitman, D., and Roskies, E. 1987. Changing everything all at once: Work life and technological change. Sloan Management Review summer:29-47.

Macey, S. 1989. The dynamics of progress: Time, method, and measure. Athens: University of Georgia Press.

Markus, M. 1983. Power, politics, and MIS implementation. Communications of the ACM 26(6):430-444.

Markus, M., and Benjamin, R. 1996. Change agentry-The next IS frontier. MIS Quarterly 20(4):385-407.

Markus, M., and Benjamin, R. 1997. The magic bullet theory in IT-enabled transformation. Sloan Management Review 38(2):5568.

Markus, M., and Robey, D. 1988. Information technology and organizational change: Causal structure in theory and research. Management Science 34(5):583-598.

Markus, M., and Tanis, C. 2000. The enterprise experience: From adoption to success. In Framing the domains of IT research: Glimpsing the future through the past, ed. R. Zmud, pp. 173-207. Cincinnati, OH: Pinnaflex Educational Resources.

Mauth, R. 1998. ERP systems are embracing component technology, so you can maintain applications quicker and easier, Byte 21, http:// www.byte.com/art/9805/sec18/art1.htm (accessed June 1999).

McClure, C., and Lopata, C. 1996. Assessing the academic networked environment: Strategies and options. Washington, DC: Association of Research Libraries.
McGrath, J. 1986. Studying groups at work: Ten critical needs for theory and practice. In Designing effective work groups, ed. P. Goodman and Associates, pp. 1-22. San Francisco: Jossey-Bass.

McGrath, J. 1988. The place of time in social psychology. In The social psychology of time: New perspectives, ed. J. McGrath, pp. 21-38. Newbury Park, CA: Sage.

McGrath, J. 1991. Time, interaction, and performance (TIP): A theory of groups. Small Group Research 22(2):147-174.

Miles, M. 1979. Qualitative data as an attractive nuisance: The problem of analysis. Administrative Science Quarterly 24:590610.

Miles, M. 1990. New methods for qualitative data collection and analysis: Vignettes and pre-structured cases. Qualitative Studies in Education 3(1):37-51.

Miles, M., and Huberman, A. 1994. Qualitative data analysis: A sourcebook of new methods. Thousand Oaks, CA: Sage.

Miller, D., and Friesen, P. 1980. Archetypes of organizational change. Administrative Science Quarterly 25:268-299.

Mohr, L. 1982. Explaining organizational behavior. San Francisco: Jossey-Bass.

Monge, P. 1990. Theoretical and analytical issues in studying organizational processes. Organization Science 1(4):406-430.

OECD. 1998. The software sector: A statistical profile for selected OECD countries. Committee for Information, Computer and Communications Policy, Directorate for Science, Technology and Industry, Organization for Economic Co-operation and Development, Report DSTI/ICCP/ AH(97)4/REV1 at http://www.oecd.org/dsti/sti/it/infosoc/stats/software.htm (accessed September 20, 1999).

Orlikowski, W. 1996. Improvising organizational transformation over time: A situated change perspective. Information Systems Research 7(1):63-92.

Orlikowski, W., and Iacono, S. 2001. Desperately seeking the "IT" in IT research-A call to theorizing the IT artifact. Information Systems Research 12(2):121-124.

Perlow, L. 1999. The time famine: Toward a sociology of work time, Administrative Science Quarterly 44(1):57-81.

Quintas, P. 1994. Programmed innovation?: Trajectories of change in software development. Information Technology and People 7(1):2547.

Reder, S., and Schwab, R. 1990. The temporal structure of cooperative activity. CSCW 90 Proceedings, pp. 303-316. Baltimore, MD: ACM.

Robinson, J., and Godbey, G. 1997. Time for life: The surprising ways Americans use their time. University Park, PA: Pennsylvania State University Press.

Romanelli, E., and Tushman, M. 1994. Organizational transformation as punctuated equilibrium: An empirical test. Academy of Manage ment Journal 37(5):1141-1166.

Sawyer, S. 2001. Information systems development: A market-oriented perspective. Communications of the ACM 44(11):97-102.

Schein, E. 1992. Organizational culture and leadership, 2nd ed. San Francisco: Jossey-Bass.

Slocombe, T., and Bluedorn, A. 1999. Organizational behavior implications of the congruence between preferred polychronicity and experienced work-unit polychronicity. Journal of Organizational Behavior 20:75-99.

Sproull, L., and Kiesler, S. 1991. Connections: New ways of working in the networked organization. Cambridge, MA: MIT Press. 
Suchman, L. 1987. Plans and situated actions. Cambridge, MA: MIT Press.

Swartz, D., and Orgill, K. 2001. Higher education ERP: Lessons learned. Educause Quarterly 24:20-27.

Tushman, M., Newman, W., and Romanelli, E. 1986. Convergence and upheaval: Managing the unsteady pace of organizational evolution. California Management Review 29(1):29-44.

Van Manaan, J. 1995. Style as theory. Organization Science 6(4):132143.

Vinton, D. 1992. A new look at time, speed, and the manager. Academy of Management Executive 6(4):7-16.

Weick, K. 1990. Technology as equivoque: Sensemaking and new technologies. In Technology and organizations, eds. P. S. Goodman, L. S. Sproull, and Associates, pp. 1-44. San Francisco: Jossey-Bass.

Wellman, B., Salaff, J., Dimitrova, D., Garton, L., Gulia, M., and Haythornthwaite, C. 1996. Computer networks as social networks:
Collaborative work, telework and virtual community. Annual Review of Sociology 22:213-238.

Wellman, B. 2001. Computer networks as social networks. Science 293(14):2031-2034.

Woods, D., and Patterson, E. 2001. How unexpected events produce an escalation of cognitive and coordinative demands. In Stress, workload, and fatigue, eds. P. Hancock and P. Desmond, pp. 290-302. Mahwah, NJ: Lawrence Erlbaum Associates.

Yin, R. 1984. Case Study Methodology. London: Sage Publications.

Young, M. 1988. The metronomic society. Cambridge, MA: Harvard University Press.

Zerubavel, E. 1979. Patterns of time in hospital life. Chicago: University of Chicago Press.

Zerubavel, E. 1981. Hidden rhythms: Schedules and calendars in social life. Chicago: University of Chicago Press.

Zuboff, S. 1988. In the age of the smart machine: The future of work and power. New York: Basic Books. 